\title{
CASO MARGARIDA MARIA ALVES: UMA DEMONSTRACÃO DO DESAFIO BRASILEIRO À PROTEÇÃO MULTINÍVEL DE DIREITOS HUMANOS
}

\author{
MARGARIDA MARIA ALVES: A DEMONSTRATION OF THE \\ BRAZILIAN CHALLENGE TO THE PROTECTION OF HUMAN \\ RIGHTS \\ Paula Arruda ${ }^{1}$ \\ João Gabriel Soares ${ }^{1}$
}

\section{Recebido em: 26/02/2018 Aceito em: 14/01/2019 \\ paularruda_pa@yahoo.com.br jgabrielcsoares@hotmail.com}

Resumo: O presente artigo objetiva discutir a proteção multinível de direitos humanos em relação ao caso Margarida Maria Alves, cuja repercussão histórica, social e política é bastante conhecida como um movimento de resistência às elites econômicas da região do brejo paraibano. Neste sentido, vê-se que ainda não houve resposta satisfatória ao caso, havendo denúncia das violações a direitos, garantias e liberdades ao Sistema Interamericano de Direitos Humanos, cuja admissibilidade foi realizada pela Comissão, ainda sem julgamento meritório. Por fim, dentro de uma análise propositiva, argumenta-se um pressuposto diálogo entre os diferentes níveis e propõe-se a realização de uma relação precedente à decisão anteriormente proferida pela Corte Interamericana sobre direitos dos trabalhadores no Brasil.

Palavras-chave: Caso Margarida Alves. Desafio Brasileiro. Direitos Humanos. Proteção Multinível. Sistema Interamericano de Direitos Humanos.

Abstract: The present article aims to discuss the multilevel protection of human rights in relation to the Margarida Maria Alves case, whose historical, social and political repercussion is well known as a resistance movement to the economic elites of the region of Paraíba. In this sense, there is still no satisfactory response to the case, and there has been a denunciation of violations of rights, guarantees and freedoms to the Inter-American Human Rights System, whose admissibility has not yet been merited. Finally, within a propositional analysis, a presupposition is argued for a dialogue between the different levels and it is proposed to carry out a previous relation to the decision previously given by the Inter-American Court on workers' rights in Brazil.

Keywords: Margarida Alves. Brazilian Challenge. Human Rights. Multilevel Protection. InterAmerican System of Human Rights.

\section{INTRODUÇÃO}

O processo histórico de formação da identidade brasileira está inexoravelmente relacionando à colonização de não-ocupação, que não tinha intuito de permanecer no local a melhor desenvolvê-lo, mas apenas o intuito de exploração e extirpação dos direitos de propriedade e dos recursos naturais locais. Desde o início, esta relação entre colonizadores e colonizados se pautou em violências e aproveitamento particular do poder por parte daqueles que possuíam latifúndios e hegemonia.

Desta forma, a dominação se deu primeiramente pela exploração colonial fixada pelo critério da raça, desta forma impondo métodos históricos de controle e sujeição, seja do trabalho, da cultura

\footnotetext{
${ }^{1}$ Universidade Federal do Pará - UFPA - Belém - Pará - Brasil
} 
ou dos recursos, a fim de garantir retorno de capital e progresso econômico, à margem da aculturação dos povos originários. Então, a raça fez legitimar a dominação conquistada, rapidamente sujeitando algumas categorias a condições de superiores, enquanto que outros eram os colonizados e explorados. Impuseram padrões de comportamento, padrões de poder que freavam toda manifestação de cultura local.

Os trópicos ao Sul, latino-americanos, sentem as consequências deste desmantelamento do direito dos povos indígenas, quilombolas, trabalhadores rurais e populações tradicionais até hoje, tendo em vista que uma perspectiva desenvolvimentista e de capital econômico de controle das condições de trabalho e propriedade de terras fora historicamente favorável aos brancos europeus, políticos e empresários, explorando economicamente até hoje os recursos naturais, através do trabalho escravo e não-reconhecimento de seus direitos básicos, reconhecidos como direitos formais nas legislações trabalhistas brasileiras, mas distante de implementação e fiscalização em territórios mais distantes. Desta forma, conforme Vera Maria Candau:

a maior parte dos cidadãos latino-americanos tem pouca consciência de que são sujeitos de direito. Esta consciência é muito débil, as pessoas inclusive por ter a cultura latino-americana uma forte marca paternalista e autoritária - acham que os direitos são dádivas. Os processos de educação em direitos humanos devem começar por favorecer processos de formação de sujeitos de direito, no nível pessoal e coletivo, que articulem as dimensões ética, político-social e as práticas concretas. Outro elemento fundamental na educação de direitos humanos é favorecer o processo de "empoderamento" ("empowerment"), principalmente orientado aos atores sociais que historicamente tiveram menos poder na sociedade (CANDAU, 2009, p. 71).

De certa forma, é importante enfatizar que a luta por tais direitos convive em um espaço onde a sobrevivência também pulsa, ou seja, a população de trabalhadores rurais dificilmente tem escolha ou sabe discernir sua condição, sujeitando-se às condições precárias e violentas de trabalho que claramente violam sua perspectiva humana. Nesse contexto, alguns movimentos de resistência cotidianamente se destacam por enxergar a gravidade da situação de exploração dos trabalhadores do campo e dedicam vidas à luta por condições minimamente dignas de trabalho, demandando à Justiça do Trabalho a materialização das garantias básicas de uma relação trabalhistas, formalmente expostas pela CLT.

Mais especificamente, no município de Alagoa Grande, interior da Paraíba, é necessário lembrar a memorável atuação de Margarida Maria Alves, que engendrou um movimento de resistência contra pressupostos materiais de dominação política, social e jurídica dos detentores de maior capital simbólico-econômico da região, historicamente hegemônico através da industrialização e captação de propriedade privada que é utilizada como forma de dominação àqueles outros que não possuem a mesmas oportunidades e se tornam dominados, visto que foram paulatinamente alijados da observação de seus direitos mais básicos, violados em sua dignidade pelo processo de reificação do indivíduo pela exploração da sua mão-de-obra em detrimento do lucro exponencial desenvolvimentista de poucos.

Revista do Direito [ISSN 1982-9957]. Santa Cruz do Sul, v. 3, n. 56, p. 45-65, set/dez. 2018. https://online.unisc.br/seer/index.php/direito/index 
Dito isto, é imperioso afirmar que este desbalanceamento existencial perpassa pelos mais diferentes níveis de nossa sociedade, desde representatividade política dessas lutas até a manutenção jurídica conservadora daqueles que veem o outro (a serviço dos que detém poder hegemônico) como um meio na execução do que seria "naturalmente" posto, olvidando a construção histórica desigual de poder entre trabalhadores rurais - que poderiam ser quaisquer outras minorias e latifundiários.

Nesta senda, cabe destacar que o conceito de proteção multinível e o estágio internacional deste caso perfeitamente se relacionam, a demonstrar uma compreensão falha do nível nacional de proteção de direitos humanos no presente caso e demandar uma melhor articulação ao desafio brasileiro quanto à proteção em diferentes níveis.

\section{PROTEÇÃO MULTINÍVEL DE DIREITOS HUMANOS E SEUS DEFENSORES}

Sendo relevante a perspectiva de investigação dos direitos humanos para além da proteção formal abarcada por tratados internacionais, os graves danos e violações às garantias humanas ocorrem à margem também, sendo necessário argumentar uma proteção em diferentes níveis (URUEÑA, 2014) não envolvendo apenas a atuação judicial de tribunais, mas que implique na efetivação de normas de direitos humanos também nos mais diversos âmbitos. Portanto, resignificar a proteção por meio da perspectiva multinível se configura a compreender a promoção dos direitos humanos em diversos níveis, inclusive frente ao caso discutido neste trabalho, por logo será compatibilizada a atuação de defensores de direitos humanos, especificamente à atuação da sindicalista e proteção multinível destes direitos, nos termos abaixo dispendidos.

\subsection{A atuação dos defensores de direitos humanos}

Nesta senda, o movimento de resistência da sindicalista se configura dentro de uma atuação em defesa dos direitos humanos, revelando a compreensão de uma ampla categoria de defensores necessária à discussão do caso. Por logo, é importante revelar que existe uma compreensão jurídica que entende quem são os defensores de direitos humanos e, conforme um conceito de amplitude significativa, inclui também sindicalistas, integrantes de ONG's, religiosos, líderes comunitários, lideranças rurais de trabalhadores sem terra, líderes quilombolas e indígenas, agentes públicos, advogados, ambientalistas, portanto se vê um claro complexo de ação para a salvaguarda de direitos humanos de outros sujeitos e assim o são definidos pelo conceito trazido pela Declaração da ONU. Em realidade, mesmo com a intensa regulamentação neste sentido, a prática demonstra pouco avanço quanto à proteção de violações de direitos deste grupo, tal como demonstrado pelo caso analisado. Defensores são

[...] indivíduos, grupos e órgãos da sociedade que promovem e protegem os direitos humanos $e$ as liberdades fundamentais universalmente 
reconhecidas (Declaração dos direitos e responsabilidades dos indivíduos, Grupos e órgãos da Sociedade para Promover e Proteger os Direitos Humanos e Liberdades Individuais universalmente reconhecidos, adotada pela Assembleia Geral das Nações Unidas, na Resolução 35/144, de 09 de dezembro de 1998). Na ampla conceituação desta Declaração, são defensores dos direitos humanos todos os homens, mulheres ou entidades que atuam promovendo e defendendo direitos ou denunciando as violações desses direitos. [Por conseguinte], os defensores de direitos humanos são pessoas que se dedicam a lutar incansavelmente pela ética, pelos valores humanitários e pelo respeito aos direitos da pessoa humana. Portanto, garantir a atuação dos defensores dos direitos humanos é lutar pelo Estado democrático de Direito (BRASIL, Plano Nacional de Educação em Direitos Humanos, 2007).

Como iniciado, o grupo dos defensores é extremamente vulnerabilizado a grandes grupos econômicos, sendo alvo além de violações físicas, se estendendo a processos de difamação, criminalização e vitimização e, dentro do conceito de Marco Apolo Leão (2008), difamação é atacar a imagem do grupo, criminalizar é imputar suas condutas como criminosas e vitimizar é efetivamente a expressão das violações de direitos que os defensores sofrem e reiterando os termos dispendidos, o autor escreve que

[...] a primeira forma destas violações denominamos de 'processo de difamação ou demonização dos DDHs. À segunda forma é o que chamamos de 'criminalização de movimentos sociais e de defensores/as de direitos humanos'. E o terceiro momento consiste na 'vitimização de defensores/as de direitos humanos' [...]. O processo de criminalização dos movimentos e lideranças sociais pode se dar de forma isolada ou em conjunto com outras formas de violação [...]. A vitimização configura-se em ameaças, violências e outros crimes que são feitos para impedir que o/a defensor/a ou uma determinada organização continue com sua atuação ou mesmo como retaliação ou vingança (LEÃO, 2008, p. 99).

Sendo necessário rememorar todos estes conceitos e gravoso perceber que há omissão estatal para investigação de denúncias e ausência de órgãos para adequar tal promoção e defesa de direitos humanos e muitas vezes esta omissão e ausências se relaciona diretamente com a violência, uma hegemonia econômica, social e racial é claramente evidenciada nas políticas de direitos humanos, pois costumam trazer um pensamento e concepções dominantes, sendo importante promovê-los, mas, sobretudo, refletir sobre sua historicidade, conforme abaixo despendido.

Por fim, com base nesta problemática apresentada de violações sofridas pelos defensores de direitos humanos, é sensato buscar uma complementação à proteção multinível destes direitos.

\subsection{Direitos humanos em diferentes níveis: a proteção multinível de direitos}

Ressalta-se que a reflexão deste trabalho terá por base a argumentação sobre proteção multinível de direitos humanos a partir do ponto de vista apresentado por René Urueña (2014) como referencial teórico metodológico de análise, sendo reconhecidas as leituras sobre 
transconstitucionalismo ${ }^{2}$, constitucionalismo multinível ${ }^{3}$ e as tendências do constitucionalismo global ${ }^{4}$ acerca das garantias de direitos, porém não adotadas justamente pelo intento de ressaltar a dimensão de proteção horizontal desta pesquisa.

Para ser possível entender proteção multinível, é necessário separar seu conceito em duas dimensões: sendo a primeira com foco no problema da governança multinível, ou seja, o aspecto político-econômico, e a segunda seria a aplicação para a proteção dos direitos humanos e essa distinção entre as duas dimensões deve ser considerada por todo o trabalho. Nesta segunda perspectiva, valoriza-se mais a garantia de direitos e não a governança, porém, para uma análise completa e complementar, ambas devem ser compreendidas conjuntamente, dentro de articulações político-governamentais para efetivar a proteção humanista.Nesta senda, há uma dimensão jurídica de direitos humanos oriunda da governabilidade e articulação europeia, tal como exposto.

A ideia de "governação multinível" tem origem nos debates sobre a integração europeia nos primeiros anos da década de noventa. Em geral, a ideia surgiu como uma reação ao paradigma dominante até esse momento, explicando a integração europeia como um processo no qual os protagonistas foram os governos centrais dos Estados-membros (como a Alemanha ou a França). Contrariando essa visão, o processo de integração europeia parecia criar certos espaços nos quais o mesmo assunto foi sujeito, ao mesmo tempo, à regulação adotada por instituições do âmbito subnacional (como uma província ou um município), nacional (como um ministério) e até mesmo supranacional (por exemplo, Comissão Europeia). Assim, embora o governo central dos Estados-membros não desaparecia como ator do projeto de governação europeia , a realidade é que existiam muitos outros atores, atuando tanto no âmbito nacional, como subnacional e supranacional. Por isso, o europeu poderia ser descrito como um modelo "multinível", porque estava composto por governos nacionais, mas também por instituições que existiam num plano mais além do tradicional Estadonação (URUEÑA, 2014, p. 16).

${ }^{2}$ Como referências bibliográficas à argumentação de um transconstitucionalismo, seguem:

a) NEVES, Marcelo. Do diálogo entre as Cortes Supremas e a Corte Interamericana de Direitos Humanos ao transconstitucionalismo na América Latina. Revista de Informação Legislativa, v. 201, p. 193-214, 2014;

b) NEVES, Marcelo. Transconstitucionalismo. 1를 edição. São Paulo: WMF Martins Fontes, 2009, v. 1 .

${ }^{3}$ Como referências bibliográficas ao constitucionalismo multinível, seguem:

a) PERNICE, Ingolf. La dimensión global del Constitucionalismo Multinivel Una respuesta legal a los desafíos de la globalización. Madrid, CEU Ediciones, 2012, p. 29. Disponível em: http://www.idee.ceu.es/Portals/0/Publicaciones/Docuweb\%20doc\%20\%2061\%20UE.pdf. Acesso em: 24/02/201;

b) PERNICE, Ingolf. Multilevel constitutionalism and the Treaty of Amsterdam: European constitutionmaking revisited. Common Market Law Review, ํㅜ 36, 1999, p. 703-750

c) FIGUEIREDO, Marcelo; CONCI, Luiz Guilherme Arcaro (coord.); GERBER, Konstantin (ORG.) A Jurisprudência e o Diálogo entre Tribunais: a proteção dos direitos humanos em um cenário de constitucionalismo multinível. Rio de Janeiro: Lumen Juris, 2016.

${ }^{4}$ Como referências bibliográficas para constitucionalismo global, seguem:

a) CANOTILHO, J. J. Gomes. "Brancosos" e interconstitucionalidade: itinerários dos discursos sobre a historicidade constitucional. 2. ed. Almedina: Coimbra, 2008;

b) RIBEIRO, Daniela Menegotti; ROMANCINI, Malu. A Teoria da Interconstitucionalidade: uma análise com base na América Latina. Revista de Direito Internacional, Braspília, vol. 12, oㅡ 2, 2015, p. 159174.

Revista do Direito [ISSN 1982-9957]. Santa Cruz do Sul, v. 3, n. 56, p. 45-65, set/dez. 2018. https://online.unisc.br/seer/index.php/direito/index 
Trata-se de um conceito que não é corrente nem comum na literatura jurídica pátria, ou seja, falar sobre proteção multinível ainda possui muitos debates e ensaios acadêmicos a seu respeito, mesmo com a importância do conteúdo relevado, reconhecendo a necessidade de maior divulgação dos seus termos, pressupostos através da necessidade de melhor conhecimento da realidade prática a partir de estudos teóricos e jurisprudenciais sobre direitos humanos.

Demais disso, no continente europeu, os direitos humanos têm proteção em quatro níveis. No âmbito subnacional, Urueña (2014) relaciona com a hierarquia à ordem constitucional do país, quando legislações infraconstitucionais consagram direitos humanos; no âmbito nacional, seria o reconhecimento constitucional em $\mathrm{si}$, as garantias revestidas como direitos fundamentais que em muito devem ser condizentes com os direitos humanos reconhecidos internacionalmente; no âmbito supranacional, fala da expansão jurisprudencial do Tribunal de Justiça da União Europeia e consagração da Carta de Direitos Fundamentais, conjugando suas forças à defesa dos direitos humanos e; no âmbito internacional, o foco é o Sistema Europeu de Direitos Humanos, cuja proteção se dá através da competência judicante da Corte Europeia de Direitos Humanos, competente apreciar os casos de violação a direitos humanos. Estas garantias não são estanques, portanto, mas sim complementares, possibilitando uma proteção mais ampla e possivelmente mais completa dos direitos humanos.

Na América Latina, este problema de proteção multinível pressupõe uma nova abordagem, afinal não é reconhecido o âmbito supranacional ${ }^{5}$. Portanto, existe a proteção no âmbito nacional, proporcionada pelos Estados constantes na região, assim como proteção internacional, primordialmente com o Pacto de San José da Costa Rica e a existência do Sistema Interamericano de Direitos Humanos, porém as experiências de conformação jurídica do Mercosul e da Comunidade Andina não permitem entender um âmbito supranacional de proteção e inúmeras tentativas tentam alcançar este âmbito, a proporcionar uma experiência de proteção em quatro níveis, porém são vários os problemas para conseguir implementar este quarto âmbito de proteção.

Segundo Urueña (2014), na experiência do Mercosul, a Carta de Direitos Humanos não avançou e mesmo os inúmeros documentos de cooperação intergovernamental na região não conseguem efetivamente criar um sistema de proteção supranacional, tais como a Reunião de Altas Autoridades na área de Direitos Humanos (RAADH), não há um sistema comunitário de direitos humanos no Mercosul, a vincular tanto os Estados quanto a organização internacional.

\footnotetext{
${ }^{5} \mathrm{Em}$ verdade, a adoção de um sistema neste sentido foi viabilizado, mas recusado por acharem que a sua criação seria contraproducente à atuação já realizada no Sistema Interamericano de Direitos Humanos, acabaria inutilizando o trabalho, portanto.
} 
Em similar ideia, a Comunidade Andina não consegue abordar também um sistema de proteção supranacional de direitos humanos. Ao passo desta ideia, já existiu um caso submetido ao Tribunal Andino, porém este foi declarado incompetente por força do Estatuto Geral do Parlamento Andino, assim como já houve esforço para um documento significativo na defesa de direitos humanos na região, mas a Carta Andina para a Promoção e Proteção dos Direitos Humanos é muito mais um acordo entre os Estados-membros e nem sequer possui força vinculante, sendo instrumento de soft law para promoção de direitos humanos, não havendo qualquer vinculação de proteção nem conseguindo alcançar um sistema supranacional.

Justificando a ausência de um âmbito de proteção na América Latina, Urueña (2014) diz que alguns comentaristas entendem o processo de integração latino-americano como jovem e argumentam que, com tempo suficiente para tanto, haverá uma proteção comunitária de direitos humanos, entretanto o mesmo autor discorda, porque essa ideia parece presumir um único caminho possível, de proteção em quatro níveis tal como o modelo europeu o faz e entender desta forma novamente iria encontrar a resposta de problemas latino-americanos dentro da tradição europeia.

Os quatro estágios, segundo a matriz europeia de proteção, atuariam como fases de maturação humana, como a infância (proteção unicamente nacional), adolescência (proteção internacional), idade adulta (proteção supranacional). Portanto, não é cabível entender desta forma, no sentido de crescimento, mas sim desenvolver um modelo próprio de proteção à região, afinal não necessariamente será avançado confiar todas as prerrogativas protecionistas à ordem internacional e que "não está predeterminado [...] proteção supranacional dos direitos humanos [...] na América Latina - e não há nada inerente lamentável neste fato (URUEÑA, 2014, p. 23)", ou seja, não é o fato da proteção estar inserida para fora do âmbito estatal-interno que este fato garantirá uma superioridade à proteção dos direitos humanos frente os outros níveis.

Devemos entender, por fim, que é possível que haja oposição dos Estados da região à instauração do nível supranacional de proteção aos direitos humanos, justamente por poder contrastar com a jurisdição interna, porém também é cabível entender que não havendo uma dimensão supranacional na América Latina não significa não haver proteção multinível, afinal a articulação do Poder Judiciário nacional com a proteção dos direitos humanos, feita pelo Sistema Interamericano, é atinente a corresponder uma proteção em nível internacional, ao lado da proteção subnacional e da proteção nacional. Portanto, não haver uma proteção supranacional nas Américas não impede a articulação de uma proteção multinível, que se releva na articulação da jurisdição constitucional com o Sistema Interamericano de Direitos Humanos.

Em busca do fortalecimento e efetividade de normas jurídicas de proteção do ser humano, tendo em vista a violação histórica do Estado aos direitos, liberdades e garantias do indivíduo, foram erigidos sistemas regionais de proteção e um sistema global sob coordenação das Nações Unidas. Porém, é necessário compreender uma proteção multinível de direitos humanos, a melhor 
corresponder esta proteção, permitindo um diálogo ${ }^{6}$ entre as proteções internas e os patamares transnacionais, onde se justifica a atuação da sindicalista, a fim de conscientizar a região sobre a situação de violação de direitos supramencionada.

Portanto, proteger em diferentes níveis representa defesa das intervenções e violações em prol da defesa de direitos dos indivíduos, realizada em diferentes esferas (local, nacional, comunitária/supranacional e internacional), por fim habilitando o exercício de resistência aportado na ordem constitucional democrática brasileira frente garantia de direitos trabalhistas e territoriais, justamente a luta de Margarida Maria Alves, nos termos abaixo elencados:

A proteção multinível, enquanto facilitadora do acesso à justiça e aos direitos fundamentais, é importante alternativa para se pensar a formação de uma rede de proteção em torno dos Defensores de Direitos Humanos. No âmbito nacional, ferramentas como o Recurso Extraordinário e o Controle Difuso de Constitucionalidade podem retirar um caso de ameaça de morte do "anonimato" e mostrá-lo ao Brasil todo, colocando-o sob julgamento do STF. Em nível externo, pode-se pensar na ascensão ao SIDH que dá grande visibilidade e pode gerar uma política pública, através do constrangimento estatal. De uma forma ou de outra, a proteção multinível pode ajudar significativamente no combate aos processos de violência contra DDHS (ARRUDA et al, 2015, p. 164).

Por fim, o grande potencial de uma argumentação de direitos humanos pautado em proteção multinível é permitir e perseguir uma atuação que alcance diferentes níveis, concomitantes a alcançar a preservação de direitos, pressupondo dialogicidade e interação entre esferas, extremamente necessário para a compreensão da situação de violação sofrida em Alagoa Grande. Então, percebese que as principais áreas de atuação deste caso se relacionam à garantia do direito dos trabalhadores. Essas pessoas, na maior parte dos casos e por força das circunstâncias, se engajam em movimentos sociais construídos e entidades da sociedade civil organizada como estratégia de sobrevivência. Enfrentam assim, violações de grupos instalados hegemonicamente e, para coibir novas violações, como demonstrado pelo caso abaixo analisado.

\section{APRESENTAÇÃO E DESENVOLVIMENTO NACIONAL/INTERNACIONAL DO CASO MARGARIDA MARIA ALVES}

Ante a proposição de uma proteção em diversos níveis, o caso Margarida Maria Alves aponta para uma compreensão de salvaguarda de direitos humanos para além do nível nacional e internacional, que se configuraram (e ainda configuram) como insuficientes, sem respostas satisfatórias mesmo depois de um longo período, corroborando um verdadeiro desafio brasileiro à correta defesa multinível de direitos. Em síntese, será apresentada uma categorização eficiente de

${ }^{6}$ Como referência à leitura, SCHAFER, Gilberto; RAUPP RIOS, Roger; LEIVAS, Paulo Gilberto; SILVEIRA GOMES, Jesus Tupã. Diálogo entre o Supremo Tribunal Federal Brasileiro e a Corte Interamericana de Direitos Humanos: uma realidade nos dias atuais? Revista da Associação dos Juízes do Rio Grande do Sul (Ajuris), vol. 44, ํㅜ 143, p. 207-232. 
quem seria o sujeito defensor de direitos humanos, incluindo a atuação da sindicalista e, por fim, será realizada uma análise jurídica frente o procedimento de submissão do caso à Comissão Interamericana, ainda sem julgamento.

\subsection{Contextualização histórica e submissão do caso à Comissão Interamericana de Direitos Humanos}

Margarida Maria Alves é uma defensora de direitos humanos e, conforme o artigo $2^{\circ} \mathrm{XXXX}$, "os defensores dos direitos humanos são todos indivíduos, grupos e órgãos da sociedade para promover e proteger direitos humanos e liberdades individuais universalmente reconhecidos". Demais disso, a proteção a estes sujeitos consta na Declaração sobre o Direito e a Responsabilidade dos Indivíduos, Grupos ou Órgãos da Sociedade de Promover e Proteger os Direitos Humanos e Liberdades Fundamentais Universalmente Reconhecidos (Defensores de Direitos Humanos), aprovada pela Resolução no 53/144 pela Assembleia Geral das Nações Unidas (ONU), em 9 de dezembro de 1998.

Demais disso, no Sistema Interamericano de Direitos Humanos (SIDH), a Resolução no 1671, intitulada "Defensores dos Direitos Humanos e Direitos Humanos nas Américas" determina a contribuição deles à promoção, respeito e proteção dos direitos e liberdades fundamentais, a nível regional e nacional, assim como o Programa Nacional de Proteção dos Defensores dos Direitos Humanos foi estabelecido pelo Decreto Presidencial no 8.724, de 27 de abril de 2016, a nível federal.

Portanto, foi uma das figuras de maior importância no cenário paraibano de resistência no campo e expoente do movimento sindical da região, na qualidade de presidente do Sindicato dos Trabalhadores Rurais de Alagoa Grande, cargo que ocupou durante o período de 1973 até a data de seu óbito, que ocorreu em 1983. Neste interstício temporal, confrontou os maiores e mais influentes empresários da região, tendo em vista sua luta para que fossem assegurados os direitos básicos conferidos pela legislação trabalhista aos trabalhadores da região, especificamente quanto à assinatura das carteiras de trabalho, concessão de férias e $13^{\circ}$ salário, além do respeito ao limite legal da jornada de trabalho ${ }^{7}$.

Da mesma forma, a resistência travada por Margarida também estava atrelada à necessidade de acesso à terra e aos meios de produção às populações rurais. Em última análise, o movimento representava a busca pelo bem-estar econômico e social do homem do campo e a fixação à terra dos que a tornaram produtiva com o seu trabalho e de sua família. Em todo caso, a luta de Margarida

\footnotetext{
${ }^{7}$ Informações dos fatos retirada da minuta de reunião para garantir o julgamento e punição dos assassinos da sindicalista, realizada no Auditório da Federação dos Trabalhadores na Agricultura no Estado da Paraíba, em 05 de abril de 200. Acesso disponível em:

http://www.fundacaomargaridaalves.org.br/wp-content/uploads/2013/08/Minuta-da-reuni\%C3\%A3opara-grantir-a-puni\%C3\%A7\%C3\%A3o-dos-assassinos-de-Margarida-2001.pdf.
} 
representava uma única finalidade, a qual converge a uma justiça social agrária, à resolução de conflitos no campo mediante o fornecimento de garantias a trabalhadores rurais, tal como se depreende do seguinte excerto, antecipando algumas consequências jurídicas concernentes (FERREIRA, 2015).

\begin{abstract}
Margarida Alves. Presidenta do Sindicato de Trabalhadores Rurais de Alagoa Grande, Paraíba, assassinada em 12 de agosto de 1983, com participação suposta de usineiros, proprietários rurais, autoridades e servidores públicos da região. A liderança de Margarida levou à abertura de cerca de 73 Reclamações Trabalhistas contra proprietários de engenhos e fábricas de produção de canade-açúcar. Por sua atuação, recebeu ameaças e ordens para abandonar a luta sindical. Um dos acusados na ação penal que apura o crime era soldado da Polícia Militar da Paraíba. A responsabilidade civil-administrativa de delegados, juízes e outras autoridades, por omissão na apuração do crime e/ou conluio com os criminosos, não foi apurada. Conforme denúncia levada à Comissão Interamericana de Direitos Humanos, em Petição de 20 de outubro de 2000, e reconhecida no Relatório de 8 de março de 2008,71 a autoria das ameaças era atribuída ao "Grupo da Várzea", formado por donos de fábrica, deputados estaduais, federais e prefeitos da região, liderado pelo único industrial de Alagoa Grande, Aguinaldo Veloso Borges, com grande poder político no estado. De acordo com o bispo da Diocese de Guarabira, dom Marcelo Pinto Cavalheira, Margarida Alves teria declarado que os autores das ameaças recebidas por ela eram integrantes do referido grupo de fazendeiros e políticos, os "Potentados de Alagoa Grande" (na expressão da vítima). Aos 50 anos, esta trabalhadora rural e militante da luta por direitos trabalhistas foi assassinada em sua residência com um tiro à queima-roupa. Familiares e vizinhos testemunharam o crime, cujo autor não se deu ao trabalho de esconder o rosto, de tão seguro que se sentia de sua impunidade (BRASIL, Comissão Nacional da Verdade, 2014, p. 116).
\end{abstract}

A postura proativa da sindicalista, no sentido de conscientizar e denunciar a situação de abuso a qual se submetiam os trabalhadores rurais culminou no manejo e ajuizamento de diversas ações trabalhistas em face dos usineiros da região, sobretudo os integrantes do denominado "Grupo Várzea", que era liderado pelo proprietário da Usina Tanques. Em razão disso, a sindicalista teve sua morte encomendada pelos fazendeiros da região, sendo assassinada em 12 de agosto de 1983 na frente de sua casa com um tiro de escopeta na face, na presença de seu esposo e seu filho.

Por conseguinte, corroborando o referido,

[...] foi assassinada em sua residência com um tiro de arma de fogo disparado à queima-roupa. A denúncia sustenta que o crime foi cometido na presença de familiares e vizinhos da vítima, sem que o ator material escondesse o rosto, com o claro propósito de intimidação e mostra de poder e, ainda, que teria a participação direta de agentes públicos fora do exercício da função. Além disso, a omissão dos agentes de Estado em várias instâncias, fez com que resultassem infrutíferas as diligências que seguiram a abertura do Inquérito Policial IP № 023/83 (segundo a denúncia na $\mathrm{CIDH}$, para efeitos de investigação a polícia não considerou seriamente a linha investigativa de que o crime tinha sido motivado pelo papel desempenhado por Margarida Alves na defesa dos direitos dos trabalhadores rurais), a abertura da Ação Penal № 183/83 pelo Ministério Público na Comarca de Alagoa Grande (acusados Amaro José do Rego, 
Amauri José do Rego e Antônio Carlos Coutinho) e a Ação Penal no 372/95 (acusados Betânio Carneiro dos Santos e José Buarque de Gusmão Neto). A morte de Margarida Alves, para além da individualidade do crime, representa uma violência contra sua família, contra as mulheres camponesas e contra todos os trabalhadores rurais que reivindicam seus direitos (BRASIL, Comissão Camponesa da Verdade, 2014, p. 148).

Neste sentido, consequentemente foi instaurado inquérito policial com finalidade de apurar a autoria delitiva do homicídio, no entanto, a maior parte das diligências empreendidas mostraram poucos resultados práticos, em razão da forte influência dos investigados dentro da região, o que fez com que as testemunhas negassem conhecimento sobre os fatos após sofrerem ameaças e atos de hostilidade por parte dos fazendeiros locais.

Ao final, foi ajuizada a Ação Penal no 183/83, em face de Antônio Carlos Coutinho, filho de um fazendeiro local, e aos irmãos Amauri e Amaro Rêgo, executores materiais do homicídio. Demais disso, o processo foi suspenso em relação aos irmãos, que estavam foragidos, e Antonio Carlos foi a julgamento em 1988, tendo sido absolvido por insuficiência probatória, vez que as provas colhidas eram eminentemente testemunhais. A decisão foi mantida em acórdão proferido pelo Tribunal de Justiça da Paraíba, em sede de julgamento do recurso de apelação interposto pelo Ministério Público.

A omissão do Estado tornou infrutíferas as diligências subsequentes à abertura do inquérito IP no 023/83, e a polícia desconsiderou a suspeita de que o crime tenha sido motivado pelo papel de Margarida em defesa dos direitos dos trabalhadores rurais. Também foram infrutíferas a Ação Penal no 183/83 contra os acusados Amaro José do Rego e Antônio Carlos Coutinho, assim como a Ação Penal no 732/95, contra Betânio Carneiro dos Santos e José Buarque de Gusmão Neto, ambas promovidas pelo Ministério Público da Comarca de Alagoa Grande, apesar da repercussão nacional e internacional do crime - a exemplo da criação da Fundação de Defesa dos Direitos Humanos Margarida Maria Alves, pelo Centro de Defesa dos Direitos Humanos da Arquidiocese da Paraíba (BRASIL, Comissão Nacional da Verdade, 2014, p. 116).

Devido à sobrevinda de novas provas ao caso (depoimento apresentado por uma nova testemunha no ano de 1986), corroborando a relação do grupo Várzea com o assassinato da líder sindical, as investigações foram retomadas somente no ano de 1991 mediante a instauração de novo inquérito policial, que culminou na denúncia de quatro novos acusados, apontados como mandantes do crime: Aguinaldo Veloso Borges, Zito Buarque, Betâneo Carneiro e Manzino, dando início à Ação Penal no 372/1995.

Todavia, um dos acusados teve decisão favorável extinguindo sua punibilidade ante o decurso do prazo prescricional e os outros dois faleceram no curso do processo, tendo apenas Zito Buarque sido julgado e permanecido preso preventivamente pelo período de três meses. Ao final do processo, o réu foi absolvido pelo Tribunal do Júri da Comarca de João Pessoa. Esta última decisão 
foi objeto de Apelação do Ministério Público, acolhida pelo Tribunal de Justiça da Paraíba e, posteriormente, houve a revogação da ordem de novo julgamento pelo Superior Tribunal de Justiça.

Neste sentido, a Convenção Americana previu algumas exceções à exigência do requisito de prévio esgotamento dos recursos internos e ao prazo da petição, ou seja, os requisitos não precisarão ser atendidos quando na legislação pátria não existir devido processo legal para a proteção do direito (como ocorreu no presente caso), assim como quando não tiver sido permitido acesso recursos internos ou tiver sido impedido de esgotá-los. O atraso injustificado no pedido de um sujeito que invocou uma suposta violação de direitos humanos, na jurisdição interna, também justifica uma flexibilização do requisito.

O artigo 46.2 da $\mathrm{CADH}$ estabelece algumas exceções às exigências de esgotamento dos recursos internos e o prazo para apresentação da petição quando: i) não existe na legislação interna o devido processo legal para a proteção do direito ou direitos que alegadamente tenham sido violados; ii) não tenha sido permitido a quem alegou violação dos seus direitos de acesso aos recursos da jurisdição interna, ou tenha sido impedido de esgotá-los; e iii) houve um atraso injustificado na decisão dos recursos apresentados (OSPINA; VILLARREAL, 2014, p. 160).

Por óbvio, há um sentimento geral de inconformismo e impunidade, gerados pela demora injustificada nas diligências e processo judicial em curso. Por conseguinte, o Gabinete de Assessoria Jurídica às Organizações Populares (GAJOP), o Centro pela Justiça e pelo Direito Internacional (CEJIL), o Movimento Nacional de Direitos Humanos (MNDH), a Comissão Pastoral da Terra (CPT) e a Fundação de Defesa dos Direitos Humanos Margarida Maria Alves (FDDH-MMA) levaram o caso à apreciação da Comissão Interamericana de Direitos Humanos (Relatório no 9/08. Caso 12.332), mediante a denúncia de violação dos direitos fundamentais da vítima pelo Estado Brasileiro, sob a alegação de que após o decurso de quase 20 anos (a sindicalista faleceu em 1983 e a denúncia foi realizada em 2000) do crime de homicídio não havia ocorrido condenação criminal dos responsáveis, revelando uma morosidade excessiva na prestação jurisdicional demandada e a falta de diligência do Estado na condução das investigações.

Como visto, a petição denunciante foi apresentada no ano de 2000 e autuada como caso no 12.332, cuja decisão de admissibilidade somente foi proferida em 2008 , quando ficou reconhecida a admissibilidade da denúncia, identificando a responsabilidade do Estado brasileiro pela inobservância às regras de direito internacional previstas na Convenção Americana de Direitos Humanos de obrigação geral de respeitar direitos, garantias judiciais - o que inclui a observância ao princípio da duração razoável do processo - proteção judicial, e, por fim, do direito à vida e à liberdade de associação, especificamente à violação dos seguintes artigos: artigo 8 - Direito às Garantias Judiciais e artigo 25 - Direito à Proteção Judicial, da Convenção Americana de Direitos Humanos.

No que tange à liberdade de associação, a Corte possui entendimento pacífico no sentido de que o Estado assume o dever de prevenir atentados contra as associações e sindicatos, proteger seus representantes, e, ainda, investigar eventuais violações a essa liberdade; dever este que foi 
claramente desrespeitado pelo Estado, uma vez que a morte de Margarida foi inequivocamente motivada por seu ativismo sindical e luta em prol dos trabalhadores rurais, mas é válido ressaltar que ainda não houve julgamento definitivo.

Em verdade, a Comissão tem função de monitoramento (elaboração de relatórios-aportes para a realização de recomendações aos Estados, onde são propostas diretrizes de correção ou esclarecimento para implementação de medidas tendentes a proteger direitos humanos), realização de consultas (aconselhar a melhorar o nível de cumprimentos dos direitos humanos. Em regra, tem caráter preventivo a avaliar diretamente os problemas de implementação ou a situação de efetiva violação aos direitos humanos) e função de processar petições individuais (preponderante para a determinação de responsabilidade internacional dos Estados e é compreendido através do princípio da complementariedade, ou seja, a proteção dos direitos humanos dentro do Sistema Interamericano só será iniciado perante a ineficácia dos sistemas nacionais de justiça), conforme Ospina e Villarreal (2014).

Então, ainda não houve julgamento e responsabilização, correspondendo a uma falha compreensão da proteção multinível e complicada articulação entre os níveis, por focar a atuação em uma dimensão internacional que poderia ser melhor respondida em nível local, por exemplo. Ainda há uma confiança hierárquica às dimensões nacional e internacional, por serem consideradas instâncias superiores e que responderia substancialmente melhor os problemas demandados, porém a própria atuação da sindicalista demonstra a necessidade de uma articulação regional (âmbito subnacional) para efetivação de direitos humanos, cabendo lecionar no seguinte sentido: cada caso apresentado juridicamente já perde significações simbólicas, pela frieza processual e capacidade de perda da subjetividade, então alçar estas demandas às instâncias ditas superiores torna o processo mais distante das partes, não sendo garantia alguma de melhor resposta.

Portanto, é necessário haver esta compatibilização entre diferentes níveis de proteção de direitos humanos, valorizando atuações de movimentos sociais locais e líderes regionais para além de um aspecto político-jurídico e estatal, que foge à compreensão da violação subjetiva. Nesta perspectiva, fica atinente a compreensão de integração e diálogo dentro da proteção multinível, pois standards de direitos humanos são necessários para efetiva articulação entre indivíduos e Estado em diferentes níveis.

\subsection{Aspecto Social: repercussão do caso e consequências sociais}

Não obstante os resultados infrutíferos na esfera judicial no que tange à condenação dos responsáveis pelo ocorrido, a imagem de Margarida foi imortalizada no âmbito social. Sendo Margarida Alves um símbolo de luta campesina, uma das principais formas de homenageá-la foi batizando a principal ação de massa das trabalhadoras rurais com seu nome, representando um símbolo de luta campesina, que resultou, inclusive, o nascimento da chamada "Marcha das Margaridas", homenagem à líder sindical iniciada no ano de 2000, uma manifestação dos direitos das mulheres no 
mundo, reunindo anualmente cerca de 70 mil ativistas na cidade de Brasília, ocasião em que são discutidos e reavivados os assuntos de igualdade de gênero, justiça e paz no campo. Neste sentido,

A Marcha das Margaridas integra a agenda política do Movimento Sindical de Trabalhadores e Trabalhadoras Rurais (MSTTR), de movimentos feministas e de mulheres. Vindas de todas as regiões do país, suas dezenas de milhares de participantes marcham para reivindicar direitos em favor das mulheres do campo e da floresta, denunciar as condições precárias a que estão expostas e fazer valer o reconhecimento de sua condição de sujeitos políticos e de trabalhadoras (IPEA, 2013, p. 8).

Este referido encontro fortalece a resistência iniciada e protegida pela sindicalista, assim como anseia lutar pela diminuição de desigualdades e lutar contra todas as formas de discriminação, contra a violência no campo e, como apresentado, por igualdade de gênero, paz e justiça. Ademais, fortalece especialmente a identidade estabelecida pelo movimento de mulheres do campo, pelo engajamento e inspiração pela representante da flor branca, um símbolo de paz, a se articular e atuar fortemente, fazendo com que suas vozes reverberem e sejam ouvidas tanto no Brasil quanto em outros países com problemas similares.

Demais disso, o movimento fortalece especialmente a identidade estabelecida pelo movimento de mulheres do campo, pelo engajamento e inspiração pela representante da flor branca, um símbolo de paz, a se articular e atuar fortemente, fazendo com que suas vozes reverberem e sejam ouvidas tanto no Brasil quanto em outros países com problemas similares. Dentro da importância simbólica conquistada pelo movimento,

Segundo informações divulgadas oficialmente pela Comissão Organizadora, a Marcha das Margaridas de 2000 reuniu em Brasília mais de 20 mil trabalhadoras rurais, centralizando todo o processo. Desde a primeira versão, sua estrutura organizacional é composta pela Coordenação Nacional, formada pela Comissão Nacional de Mulheres da CONTAG, representantes das Comissões Estaduais de Mulheres das Federações e de organizações parceiras. As Comissões Estaduais, Regionais e Locais são formadas pelas representantes sindicais e das organizações parceiras nos níveis que estão localizadas. As parcerias são articuladas em âmbito nacional, porém existem variações necessárias às realidades nos Estados, Municípios e Regiões [...].A MM possui ações de mobilização, formação e denúncia que a caracterizam como uma estratégia ou ação política. A organização inclui reuniões locais para discussão da pauta - chamadas de reuniões de base, lançamentos, entrega da pauta e avaliação. As reuniões e eventos para discussão da pauta são subsidiadas pelo documento ou a Carta da Marcha que contém os eixos temáticos. A partir dos temas sugeridos, novos temas são incorporados, tanto no diagnóstico e avaliação, quanto propostas para cada tema (SILVA, 2008, p. 90).

Neste contexto, também merece ressalva a Jornada das Margaridas, que se configura como uma extensão da Marcha, onde anualmente as pautas serão revisitadas e novas negociações com o governo prosseguem sendo discutidas, primando pelo resgate do caso de Margarida na justiça (até então não houve condenação de nenhum dos acusados, por prescrição ou morte dos sujeitos, e a 
Corte apenas admitiu esta demanda, sem julgá-la ainda) e seu julgamento, para que os autores (seja mandante, executor e/ou partícipes) possam ser devidamente condenados.

Após, em 1994, foi criada a Fundação de Defesa dos Direitos Humanos Margarida Alves ${ }^{8}$, entidade autônoma e sem fins lucrativos, regida juridicamente regida pela legislação fundacional. Prima por atuar frente atividades de educação popular, promovendo, assim, amplamente o acesso à justiça.

Como instrumento de resgate à sua memória, foi lançada a Campanha Margarida na Memória em 2013, estando disponibilizado mais de 35 documentos (por exemplo, atas, petições e recortes de jornal) do acervo particular da entidade, ambos relacionados ao caso. Desta forma, fortalece a memória de Margarida e instiga pesquisadores, professores, trabalhadores, mulheres e sociedade em geral a lembrar da lutada sindicalista. Reafirmando sua posição forte, existe um movimento conhecido como Mulheres do Brejo.

Seguindo na exposição dos prêmios estabelecidos, foi instituído o Prêmio Margarida Alves de estudos rurais e gêneros, destinado àqueles que lutam por melhorias diárias às condições de trabalhadores rurais. O Ministério de Desenvolvimento Agrário, atento ao caso e às demandas regionais, investiu em açudes, casas de farinha, poços artesianos e máquinas de PAC para o município de Alagoa Grande.

Como homenagem, a data da morte da sindicalista se tornou o dia Nacional da Violência no Campo e Reforma Agrária ${ }^{9}$ e uma das maiores consequências sociais para a área foi a promulgação de um decreto presidencial que declarou interesse social para fins de reforma agrária dos imóveis rurais presentes na área rural Usina Tanques/Capoeira ${ }^{10}$. Nestes termos, o Incra imitiu a posse para conseguir realizar reforma agrária, concretizando o princípio da justiça social agrária, acima exposto.

Em síntese, as palavras de Margarida ainda ecoam entre as mulheres trabalhadoras rurais e forças sindicais, mas fortalecem a luta diária pela representatividade, assim como atuando para melhores condições de trabalho e de vida no âmbito rural, mesmo trinta e três anos depois de sua morte.

Por fim, cumprindo seu intento inaugural, inúmeras ações sociais têm sido mobilizadas para fortalecer a organização sindical feminina e proteção dos trabalhadores rurais em nível nacional e internacional.

\footnotetext{
${ }^{8}$ Informação registrada pela Fundação Margarida Maria Alves. Disponível em: <http://www.fundacaomargaridaalves.org.br/homenagens/>. Acesso em: 19/06/2017.

${ }^{9}$ Informação registrada pela Fundação Margarida Maria Alves. Disponível em: <http://www.fundacaomargaridaalves.org.br/homenagens/>. Acesso em: 19/06/2017.

10 Informação registrada pela Assessoria dolncra/PB. Disponível em: http://www.incra.gov.br/noticias/incra-recebe-posse-do-imovel-usina-tanques-palco-de-luta-dacamponesa-margarida-alves. Acesso em 27/06/2017.
} 


\section{CONCLUSÃO}

Nota-se, por conseguinte, que a postura jurídica no caso da morte de Margarida Alves é a do esquecimento e da irrelevância, visto que esta tentou refutar o status quo assimétrico entre estas classes acima expostas. A crítica ao nosso sistema jurídico (e consequente falha conjugação da proteção multinível) é evidente em não ter solucionado ou punido devidamente os assassinos da sindicalista, que fora morta justamente em razão da sua insurgência contra os abusos perpetrados pelos latifundiários.

Neste aspecto, é fundamental perceber o quanto o desafio brasileiro à proteção multinível, enquanto sistema formal de normas em favor do indivíduo peca materialmente, seja pela disposição de seus agentes ao interpretar normas ou predisposição sistemática não correspondente às situações reais das relações agrárias, pois o que se vê no caso de Margarida são sucessões de erros estatais e necessidade de recorrer ao âmbito internacional para fazer valer o mínimo de justiça, que não é garantia alguma de alcance substancial.

O caso de Margarida Maria Alves é a clara demonstração de como o ordenamento brasileiro está aquém das demandas sociais e como ainda é falho na concretização ao que se propõem em defender, que é a possibilidade minimamente digna da pessoa humana em se desenvolver e ter seus direito reconhecidos, principalmente às populações que estão à margem da sociedade e do acesso à cidadania, especificamente dentro de uma compreensão de proteção multinível pouco desenvolvida em dialogicidade. Portanto, confere, neste caso, uma importância ao Sistema Interamericano de Direitos Humanos ante a insuficiência do Estado em um parâmetro nacional, contribuindo à eficiência de proteção em caso de inércia.

Constatamos um paradoxo dentro do segmento de DDH's (defensores de direitos humanos), pois se de um lado há um forte pensamento político, de resistência e luta para a conquista de direitos, o que pressupõe uma boa formação política, há uma fragilidade na própria concepção de direitos, na compreensão da dinâmica social, especialmente no que se refere à correlação de forças, na organização da sociedade e no papel de órgãos do Poder Público [...]. Pela análise desse pequeno universo de DDH's podemos afirmar que a efetivação dos direitos humanos em seu sentido amplo - econômicos, sociais, culturais e ambientais - depende, dentre outras, da adoção por parte do Poder Público de ações de combate ao racismo e de medidas que garantam equidade entre grupos raciais e étnicos e entre gêneros (OSHAI, 2008, p. 95).

Não obstante a situação de impunidade experimentada pelos responsáveis por seu assassinato é necessário afirmar que a morte da sindicalista não foi em vão, tendo em vista que a sua luta vai muito além de sua atuação no sindicato. Em um de seus discursos, a líder sindical declarou uma de suas frases mais icônicas: "é melhor morrer na luta que morrer de fome", portanto não lutar seria acovardar-se diante de uma minoria que explora o trabalho humano e retira territórios daqueles sujeitos pertencentes àquela região em favor de uma economia lucrativa. 
Neste sentido, a necessidade de organização dos trabalhadores e mobilização dos agentes prejudicados pela opressão dos grandes proprietários de terras foi registrado em importante discurso da sindicalista na comemoração do dia $1^{\circ}$ de maio de 1983, na cidade de Sapé/PB:

Eles não querem que vocês venham à sede porque eles estão com medo, estão com medo da nossa organização, estão com medo da nossa união, porque eles sabem que podem cair oito ou dez pessoas, mas jamais cairão todos diante da luta por aquilo que é de direito devido ao trabalhador rural, que vive marginalizado debaixo dos pés deles ${ }^{11}$.

Não lutar, portanto, levaria inevitavelmente à morte dos trabalhadores, ao esgotamento físico, psíquico, mas também faria morrer um propósito muito maior, o sonho por dias melhores, pelo acesso à terra, pelo respeito aos trabalhadores e as condições dignas de trabalho de um povo tão sofrido.

Desta forma, a luta de Margarida Maria Alves continua, através de uma repercussão nacional e internacional do seu caso, que deve ser compreendida dentro da necessidade de uma melhor articulação entre os níveis de proteção de direitos humanos e correspondendo a uma atual falibilidade do desafio brasileiro à proteção multinível, significando a morte brutal de uma mulher que não se amedrontou diante de poderosos e ricos homens, repercutindo até os dias atuais, sendo símbolo da luta no campo por acesso à terra, a melhoria das condições de trabalho e respeito à legislação trabalhista por parte dos grandes proprietários de terras que ainda contribui para o desenvolvimento rural e urbano sustentável, fortalecendo a agricultura familiar.

Por fim, analisando o caso apresentado, é nítida a percepção de que a denúncia tende a reparar violação de direito ao trabalho e leva progressivamente a superar uma postura de violência, impunidade e alta tolerância com a violação de direitos humanos, porém a responsabilidade estatal que justificou a admissibilidade do caso pelo Sistema Interamericano de Direitos Humanos decorre do descumprimento da obrigação da responsabilidade de investigar e punir dentro do âmbito interno, uma manifesta dificuldade de promoção da intentada proteção multinível, demonstrando uma clara tensão e desencontro entre o direito brasileiro e do direito internacional (âmbito nacional e internacional de proteção).

Neste sentido, a proteção multinível é posta dentro deste trabalho como um modelo de eficiência de diálogo interrrelacional entre instâncias judiciais e, não sendo atendida, tal como vem acontecendo no presente caso, há falibilidade do sistema de garantia de direitos, justamente o desencontro entre os âmbitos de proteção acima descritos.

É nítido perceber que o vigente sistema de justiça não consegue responder efetivamente a garantia de direitos, inclusive em relações horizontais, muito menos quando a violação for estatal, logo é necessário que os órgãos deste sistema se compatibilizam à especificada proteção de direitos humanos dentro de diferentes e múltiplos níveis, tendo como base crítica a renovação da justificação

${ }^{11}$ Excerto do discurso registrado pela Fundação Margarida Maria Alves. Disponível em: <http://www.fundacaomargaridaalves.org.br/homenagens/>. Acesso em: 19/06/2017. 
e estruturação do poder judicial, reorganizando a tradicional pura teoria à ampla proteção de direitos humanos, mesmo frente um discurso de dever ser, articulando diálogo entre direito constitucional, legislações infraconstitucionais, Sistema Interamericano de Direitos Humanos e articulações sociais e políticas regionalmente, nos termos precedentes dispendidos.

Se não for melhor articulada esta relação, dentro de um diálogo de complementariedade, o Estado brasileiro continuará sendo demandado a reparações ou condenações estipuladas pela Comissão ou Corte Interamericana de Direitos Humanos. Neste sentido, se configura

[...] pouco útil o simples transplante da aproximação europeia [...], uma nova aproximação pode ser desenvolvida a partir da ideia de interação entre nacionais e internacionais [...], é na interação que a proteção eficiente dos direitos humanos poderá ser construída na região (URUEÑA, 2014, p. 41).

A seguir, propondo uma perspectiva analítica dentro de cenários de desafios e necessidade de compreensão de uma proteção multinível, é cabível buscar precedentes sobre direito dos trabalhadores e análise propositiva, pois servem de repertório às futuras decisões da Corte Interamericana, inclusive à decisão do presente caso.

Então, é possível achar uma correlação ao Caso dos Trabalhadores da Fazenda Brasil Verde, cuja sentença foi prolatada em 20 de outubro de 2016, se referindo à prática de trabalho forçado e servidão por dívidas na referida fazenda paraense, além das declarações sobre ameaças de morte, a usurpação da liberdade de locomoção pelo consequente endividamento ao fazendeiro, a falta de salário, falta de moradia, alimentação e saúde dignas, afinal os direitos à vida e à integridade pessoal dos defensores de direitos humanos no Brasil estão intrinsecamente relacionados com a falta de um programa estatal eficaz destinado a protegê-los das ameaças e atos contra eles, o que é essencial para existir de acordo com a jurisprudência da Corte Interamericana.

Neste sentido, o Estado brasileiro foi condenado pela violação do direito de não ser submetido à escravidão e tráfico de pessoas, também sendo responsável por violar as garantias judiciais de devida diligência e de prazo razoável, previstas no artigo 8.1 da Convenção Americana sobre Direitos Humanos, em relação ao artigo 1.1 do mesmo instrumento, em prejuízo dos trabalhadores da fazenda e pela violação do direito à proteção judicial, previsto no artigo 25 da mesma Convenção.

Em síntese, foi confirmada violação à liberdade, ao acesso à justiça e garantias judiciais e, por conseguinte, à razoável duração do processo e, como recomendações, foi determinado que se reiniciem, com a devida diligência, as investigações e/ou processos penais relacionados aos fatos constatados e, se for o caso, punir os responsáveis, além de apresentar ao Tribunal um relatório, em um ano, sobre as medidas adotadas para dar cumprimento à mesma.

Ante o exposto, mesmo com as particularidades de ambos, tal precedente consegue responder, em similaridades teóricas, a proteção de direitos humanos que deveria ser atendida ao 
caso de Margarida Maria Alves, pois coíbe as violações além de indicar investigações para responsabilização dos violadores a tais garantias, sendo uma proposição necessária realizar uma relação distintiva ao caso paraibano, tendo em vista o contexto histórico diferente de violação e o direito arguido.

Neste sentido, é necessário compreendê-lo como referência decisória, que entende a dimensão do direito dos trabalhadores dentro da realidade brasileira de exploração deste direito e, sugerindo as mesmas recomendações realizadas, também deveria, propositivamente, tal futura decisão focar no fortalecimento os movimentos sociais oriundos do caso da sindicalista através de uma melhor articulação dialógica entre o Estado e tais movimentos, vinculando uma possível publicação anual de relatórios nacionais sobre a situação política e jurídica dos recentes conflitos agrários e sindicais, ajuda de custo e divulgação à Marcha e Jornada das Margaridas, entre outras recomendações atinentes à proteção.

\section{REFERÊNCIAS}

ALVARADO, Paola Andrea Acosta. El pluralismo constitucional como respuesta a los desafíos de la protección multinivel em Latinoamérica. Comentarios a la propuesta de René Urueña. Revista Derecho del Estado, núm. 31, julio-diciembre, Universidad Externado de Colombia, 2013, pp. 347368

ARRUDA, Paula; BENASSULY, André; SANTOS, Igor do Carmo. Entre a Criminalização e a descriminalização dos defensores de direitos humanos na Amazônia Paraense.In: Psicologia social, direitos humanos e históricos: transversalizando acontecimentos do presente. Flávia Cristina Silveira Lemos (org.), et ali, 1를 edição, Curitiba: CRV, 2015, p. 159-169.

BARZOTTO, Luciane Cardoso. Direitos humanos e trabalhadores: atividade normativa da Organização Internacional do Trabalho e limites do Direito Internacional do Trabalho. Porto Alegre: Livraria do Advogado Editora, 2007.

BONNA, Alexandre Pereira; LEAL, Pastora do Socorro Teixeira. Proteção Multinível de Direitos Humanos nas Relações Privadas por meio do reconhecimento dos novos danos. V Encontro Internacional do Conselho de Pesquisa e Pós-Graduação em Direito. Grupo de Trabalho Direito Internacional dos Direitos Humanos III, 2016, Montevidéu, Uruguai. Anais do Evento. Disponível em:

http://www.conpedi.org.br/publicacoes/910506b2/081s6j67/oWk6g4H1y4Lah282.pdf. Acesso em 27/05/2017.

BRASIL. Comissão Camponesa da Verdade. Relatório Final: Violações de Direitos no Campo 1946-1988. Brasília, 2014, p. 148.

BRASIL. Comissão Nacional da Verdade. Relatório: textos temáticos / Comissão Nacional da Verdade. Brasília: CNV, v. 2, 2014. 416 p.

BRASIL. Comitê Nacional de Educação em Direitos Humanos. Plano Nacional de Educação em Direitos Humanos. Brasília: Secretaria Especial dos Direitos Humanos, Ministério da Educação, Ministério da Justiça, UNESCO, 2007.

CINELLI, Catiane; JAHN, Elisiane de Fátima. A constituição de identidades camponesa e feminista no Movimento de Mulheres Camponesas. Revista Espaço Acadêmico. № 117. Fevereiro de 2011. Disponível em: 
http://www.periodicos.uem.br/ojs/index.php/EspacoAcademico/article/view/11796/6546. Acesso em: 19/06/2017.

COMISSÃO INTERAMERICANA DE DIREITOS HUMANOS. Relatório no 9/08. Caso 12.332. Admissibilidade. Disponível em:

https://cidh.oas.org/annualrep/2008port/Brasil12332port.htm. Acesso em: 19/06/2017.

CORDEIRO, Laís Vaz. O Sistema Interamericano de Proteção dos Direitos Humanos a partir do constitucionalismo multinível, do transconstitucionalismo e da interconstitucionalidade: desafios e limites. Dissertação de Mestrado defendida no Programa de Pós-Graduação Interdisciplinar em Direitos Humanos da Universidade Federal de Goiás. Disponível em: https://ppgidh.ndh.ufg.br/up/788/o/Disserta\%C3\%A7ao de Mestrado - Vers\%C3\%A3o Final La\%C3\%ADs Vaz Cordeiro.pdf. Acesso em: 24/02/2018.

CORTE INTERAMERICANA DE DIREITOS HUMANOS. Caso Trabalhadores da Fazenda Brasil Verde vs. Brasil. Sentença disponível em: http://www.corteidh.or.cr/docs/casos/articulos/seriec 318 por.pdf. Acesso em: 05/02/2018.

FERREIRA, Ana Paula Romão de Souza. A trajetória politica - educativa de Margarida Maria Alves. Disponível em: http://transformatoriomargaridas.org.br/sistem a/wpcontent/uploads/2015/02/2.-Tese-sobreMargarida-Alves.pdf. Acesso em: 27/06/2017.

FUNDAÇÃO MARGARIDA MARIA ALVES. Disponível em:http://www.fundacaomargaridaalves.org.brl. Acesso em: 19/06/2017.

LEÃO, Marco Apolo S. Defensores de direitos humanos. In: Em Defesa da vida: a realidade dos/as defensores/as de direitos humanos sob situação de risco e ameaça no Estado do Pará. Centro de Estudos e Defesa do Negro no Estado do Pará (org.). Belém: CEDENPA, 2008, p. 97-177.

OSHAI, Cristina Arêda. Quem são os/as defensores/defensoras de direitos humanos. In: Em Defesa da vida: a realidade dos/as defensores/as de direitos humanos sob situação de risco e ameaça no Estado do Pará. Centro de Estudos e Defesa do Negro no Estado do Pará (org.). Belém: CEDENPA, 2008, p. 49-97.

OSPINA, Felipe Arias; VILLARREAL, Juliana Galindo. O Sistema Interamericano de Direitos Humanos.Disponível em: Bandeira Galindo, George Rodrigo; Urueña, René; Torres Pérez, Aida (coordenadores). Proteção multinível dos direitos humanos. Manual. Barcelona: Rede Direitos Humanos e Educação Superior, 2014, p. 145-180.

SCHAFER, Gilberto; RAUPP RIOS, Roger; LEIVAS, Paulo Gilberto; SILVEIRA GOMES, Jesus Tupã. Diálogo entre o Supremo Tribunal Federal Brasileiro e a Corte Interamericana de Direitos Humanos: uma realidade nos dias atuais? Revista da Associação dos Juízes do Rio Grande do Sul (Ajuris), vol. 44, no 143 , p. 207-232.

SILVA, Berenice Gomes. A Marcha das Margaridas: resistência e permanência. Dissertação de Mestrado apresentada ao Departamento de Sociologia da Universidade de Brasília/UnB. Disponível em: http://transformatoriomargaridas.org.br/sistema/wpcontent/uploads/2015/02/Disserta\%C3\%A7ao_Berenice_jul20081-1.pdf. Acesso em: 05/02/2018.

SILVA, Vinícius; LONDERO, Josirene Candido. Marcha das Margaridas: participação e cidadania das trabalhadoras rurais. XII CONAGES - Colóquio Nacional Representações de Gênero e Sexualidade. Grupo de Trabalho Direitos Humanos, Feminismo e Políticas Públicas de Gênero. 2016. Campina Grande, Paraíba. Anais do Evento. Disponível em:

http://www.editorarealize.com.br/revistas/conages/trabalhos/TRABALHO EV053 MD1 SA8 ID48 17 042016155613.pdf. Acesso em: 27/06/2017. 
URUEÑA, René. Proteção multinível de direitos humanos na América Latina? Oportunidades, desafios e riscos.Disponível em: Bandeira Galindo, George Rodrigo; Urueña, René; Torres Pérez, Aida (coordenadores). Proteção multinível dos direitos humanos. Manual. Barcelona: Rede Direitos Humanos e Educação Superior, 2014, p. 15-48.

URUENA, René. Luchas locales, cortes internacionales. Una exploración de la protección multinivel de los derechos humanos en América Latina. Revista Derecho Estado, Bogotá, n. 30, jan. 2013, p. 301-328.

\section{COMO CITAR ESSE DOCUMENTO:}

SOARES, João Gabriel; ARRUDA, Paula. Caso Margarida Maria Alves: uma demonstração do desafio brasileiro à proteção multinível de direitos humanos. Revista do Direito, Santa Cruz do Sul, v. 3, n. 56 jan. 2019. $1982-9957$. Disponível em: <https://online.unisc.br/seer/index.php/direito/article/view/11701>. Acesso em: doi:https://doi.org/10.17058/rdunisc.v3i56.11701. 